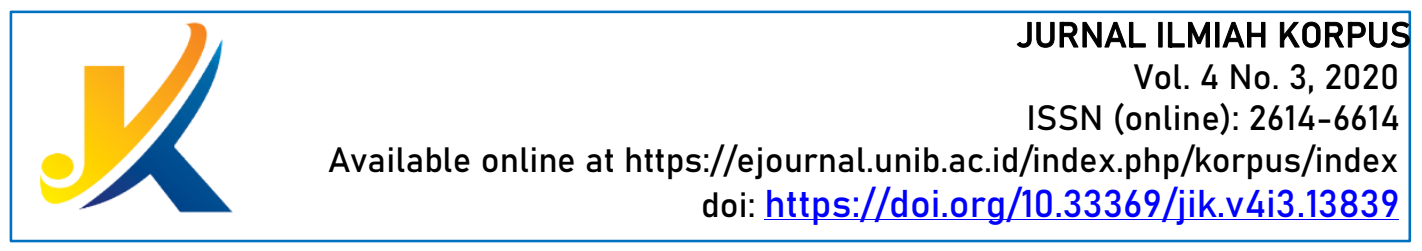

\title{
PENGAJARAN BAHASA DAN PEMEROLEHAN BAHASA KEDUA DALAM PEMBELAJARAN BIPA (BAHASA INDONESIA PENUTUR ASING)
}

\author{
Rosiyana \\ Universitas Islam Negeri Syarif Hidayatullah Jakarta
}

Abstrak

\section{Korespondensi: rosi.yana18@mhs.uinjkt.ac.id}

Bahasa merupakan alat komunikasi manusia dalam kehidupan sehari-hari, bahasa digunakan untuk menyampaikan sesuatu baik lisan maupun tulisan. Dalam pembelajaran bahasa pada BIPA dibutuhkan pengajaran bahasa yang baik agar pengajaran bahasa bagi pentur asing mudah dipahami. Penelitian ini bertujuan untuk mengetahui kesalahan mahasiswa penutur asing dalam pembelajaran bahasa Indonesia, dan untuk mengetahui pengajaran bahasa kedua dalam pembelajaran bahasa Indonesia bagi penutur asing (BIPA). Penelitian ini menggunkan metode kualitatif. Teknik pengumpulan data dalam penelitian ini (1) wawancara, (2) Kuesioner, dan (3) referensi buku. Hasil penelitian ini menunjukan bahwa penutur asing terdapat kesalahan yaitu terdapat pemilihan kata, penggunaan afiks, kesalahan pada stuktur kalimat, dan penggunaan kefektifan dalam penggunaan bahasa Indonesia. Subjek yang digunakan dalam penelitian ini adalah Pengajar BIPA yaitu Dosen UIN Syarif Hidayatullah Jakarta, dan Dosen Universitas Pakuan sebagai pengajar BIPA dengan mahasiswa asing 20 berasal dari beberapa Negara yaitu di lembaga Bimbel Education Laboratory dan Mahasiswa UIN Syarif Hidayatullah Jakarta sebagai mahasiwa penutur asing, . Agar mahasiswa asing tidak kesulitan dalam pembelajaran bahasa sebaiknya pengajar mengetahui apa kesulitan mahasiswa asing, dan pengajar harus mempunyai strategi yang kreatif agar tidak menyebabkan mahasiswa asing belajar bahasa Indonesia. Dengan penelitian ini diharapkan dapat membantu guru menjadi lebih sadar akan hal ini kesalahan karena dengan mengidentifikasi kesalahan yang bermasalah, guru mampu menghubungkan konsep dasar kalimat serta itu terkait dengan pemahaman mereka sendiri tentang konsep linguistik, bahasa dan pengajaran BIPA.

Kata Kunci: Bahasa, Penguasaan Bahasa Kedua, BIPA, Kesalahan Struktural, Pengajaran Bahasa.

\footnotetext{
Abstrak

Language is a means of human communication in everyday life, language is used to convey something both spoken and written. In language learning at BIPA, good language teaching is needed so that language teaching for foreign actors is easy to understand. This study aims to determine the mistakes of foreign speaker students in learning Indonesian, and to determine the teaching of a second language in Indonesian language learning for foreign speakers (BIPA). This research uses qualitative methods. Data collection techniques in this study (1) interviews, (2) questionnaires, and (3) book references. The results of this study indicate that foreign speakers have errors, namely there are word choices, use of affixes, errors in sentence structure, and the use of effectiveness in the use of Indonesian. The subjects used in this study were BIPA Teachers, namely UIN Syarif Hidayatullah Jakarta Lecturers, and Pakuan University Lecturers as BIPA teachers with 20 foreign
} 
students from several countries, namely in the Bimbel Education Laboratory and UIN Syarif Hidayatullah Jakarta students as foreign speakers,. So that foreign students do not have difficulties in language learning, it is better if teachers know what difficulties foreign students have, and teachers must have a creative strategy so as not to cause foreign students to learn Indonesian. With this research, it is hoped that it can help teachers become more aware of this error because by identifying problematic errors, teachers are able to connect the basic concepts of sentences and it is related to their own understanding of linguistic concepts, language and BIPA teaching.

Keywords: Language, Second Language Mastery, BIPA, Structural Error, Language Teaching.

\section{PENDAHULUAN}

Bahasa merupakan alat komunikasi manusia dalam kehidupan sehari-hari , bahasa digunakan untuk menyampaikan sesuatu baik lisan maupun tulisan. Kita sebagai manusia tidak dapat terlepas dari bahasa. Manusia merasa berbahasa sama halnya dengan kegiatan bernafas., yang dapat dilakukan sewaktu-waktu. Dalam menggunakan bahasa tidak merasa terdapat sesuatu yang rumit. Untuk itulah, manusia sering tidak menyadari bahwa kemampuan berbahasa tidak cukup hanya sekadar mengeluarkan bunyi-bunyi.

Psikolinguistik merupakan kajian yang berkaitan dengan psikologi yaitu mempelajari bahasa secara langsung, jika seseorang mengucapkan suatu kalimat kemudian si pendengar mendengarkan apa yang diucapkan ketika berkomunikasi kemudian itu dikatakan sebagai psikolinguistik.

Menurut (Nuryani: 2013: 160). Bahasa kedua adalah bahasa yang diperoleh seseorang setelah dia memperoleh bahasa pertama (bahasa ibu). Pemerolehan bahasa kedua adalah proses ketika seseorang memperoleh sebuah bahasa lain setelah terlebih dahulu ia menguasai sampai batasa tertentu bahasa pertamanya. Istilah bahasa kedua terkadang juga disamakan dengan bahasa asing. Di Indonesia, istilah bahasa pertama atau bahasa ibu mengacu pada bahasa daerah tertentu, sedangkan bahasa kedua berwujud bahasa Indonesia atau bahasa asing.

Pembelajaran BIPA merupakan proses pembelajaran yang dilakukan pentur asing untuk belajar bahasa Indonesia. Pada pengajaran bahasa untuk BIPA kegiatan belajar harus lebih detail dan lebih difokuskan pada proses pembelajaran. Karena ini sangat penting agar penutur asing tidak kesulitan dalam pembelajaran bahasa Indonesia. Pengajar juga harus mengetahui apa kesulitan pentur asing dalam belajar bahasa Indonesia, agar proses pembelajaran dapat efektif dan efesien.

Program BIPA adalah pembelajaran bahasa Indonesia yang subjeknya merupakan pembelajar asing. BIPA lebih memandang atau fokus pada pembelajarnya. Orangorang yang menjadi subjek BIPA adalah orang asing. Jadi, bahasa Indonesia merupakan bahasa asing bagi pembelajar BIPA. Pembelajaran BIPA menjadikan orang asing mampu dan menguasai bahasa Indonesia (Kusmiatun, 2016: 1). Sedangkan pelajar BIPA adalah pelajar dari luar negara Indonesia yang ingin belajar bahasa Indonesia. Pelajar tersebut biasanya terdiri dari warga negara asing yang belum mengerti dasar dan tata bahasa Indonesia tetapi tertarik untuk mempelajarinya. Hal tersebut didukung dengan pernyataan dari Suyitno (2008: 111) bahwa pelajar BIPA merupakan pelajar berkewarganegaraan asing yang memiliki latar belakang budaya berbeda dengan budaya bahasa yang diketahui dan dipelajarinya selama ini. 
Berdasarkan hasil wawancara dengan Dosen Universitas Pakuan bahwa mahasiswa asing di lembaga Bimbel Education Laboratory dalam pemebelajaran bahasa Indonesia terdapat kesulitan terdapat pemilihan kata, penggunaan afiks, kesalahan pada stuktur kalimat, dan penggunaan kefektifan dalam penggunaan bahasa Indonesia. Maka dalam pengajaran bahasa bagi penutur harus di fokuskan dimana letak kesalahan mahasiswa penutur asing dalam proses pembelajaran agar proses pembelajaran mahasiswa asing berjalan dengan efektif.

Alasan peneliti mengambil penelitian mengenai "Pengajaran Babasa Dan Pemerolehan Bahasa Kedua Dalam Pembelajaran Bipa (Bahasa Indonesia Penutur Asing) "karena peneliti ingin mengetahui pengajaran seperti apa yang dilakukan Dosen Universitas Pakuan dalam mengajar mahasiswa asing di lembaga Bimbel Education Laboratory. Kesalahan apa saja yang dilakukan mahasiswa asing yang belajar di bahwa mahasiswa asing di lembaga Bimbel Education Laboratory dalam pembelajaran bahasa Indonesia.

Oleh karena itu peneliti tertarik mengambil meneliti "Pengajaran Bahasa Dan Pemerolehan Bahasa Kedua Dalam Pembelajaran Bipa (Bahasa Indonesia Penutur Asing”. Dengan menggunakan metode kualitatif. Dengan penelitian ini diharapkan dapat membantu guru menjadi lebih sadar akan hal ini kesalahan karena dengan mengidentifikasi kesalahan yang bermasalah, guru mampu menghubungkan konsep dasar kalimat serta itu terkait dengan pemahaman mereka sendiri tentang konsep linguistik, bahasa dan pengajaran BIPA.

\section{METODE PENELITIAN}

Dalam penelitian ini saya menggunakan metode penelitian data kualitatif, Yaitu Peneliti menggunakan analisis wawancara Pengajar BIPA yaitu Dosen UIN Syarif Hidayatullah Jakarta, dan Dosen Universitas Pakuan sebagai pengajar BIPA dengan mahasiswa asing 20 berasal dari beberapa Negara yaitu di lembaga Bimbel Education Laboratory dan Mahasiswa UIN Syarif Hidayatullah Jakarta sebagai mahasiwa penutur asing, untuk menentukan bagaimana pengajaran bahasa BIPA dan kesulitan mahasiswa asing ketika belajar bahasa Indonesia dengan mengisi kuesioner. Pengumpulan data dengan menggunakan (1) wawancara, (2) Kuesioner, dan (3) Referensi Buku.

\section{HASIL DAN PEMBAHASAN}

a) Pengajaran Bahasa Kedua Dalam Pembelajaran BIPA di Lembaga Bimbel Education Laboratory

Hasil penelitian yang dilakukan dalam mewawancari Dosen Universitas Pakuan sebagai pengajar BIPA mahasiswa asing 20 mahasiswa berasal dari beberapa Negara di lembaga Bimbel Education Laboratory. Bahwa pengajaran BIPA di lembaga Bimbel Education Laboratory menggunakan metode pengajaran : (1) Tingkat dasar, yaitu seoarang guru menejelaskan dengan secara langsung kepada mahasiswa dengan mengenalkan benda-benda, atau yang lainnya yang ada disekitarnya, dalam bentuk kata bahasa Indonesia dengan mengenalkan secara berulang-ulangan. (2) Tingkat mahir, yaitu guru melakukan pengajaran dengan menggunkan kesulitan- kesulitan yang dihadapi mahasiswa asing dalam pembelajaran bahasa, jadi guru mengajarkan dengan kesesuaian dimana kesulitan nya.

Berikut ini hasil presentase mahasiswa asing di lembaga Bimbel Education Laboratory: 


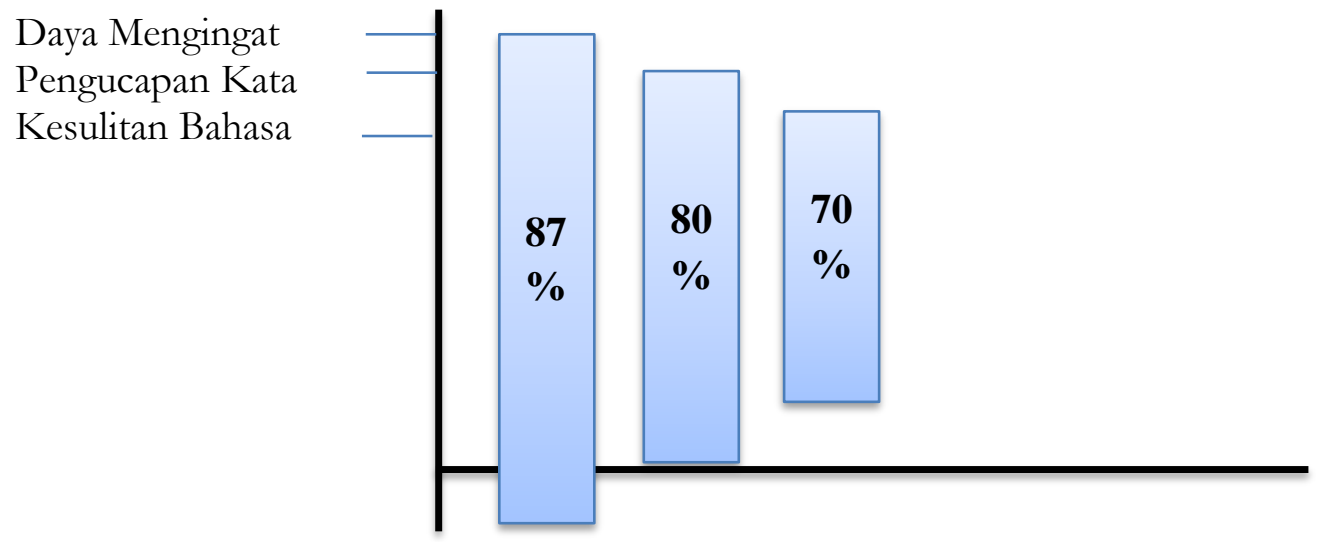

\section{Gambar 1. Diagram hasil Pengajaran mahasiswa asing di lembaga Bimbel Education Laboratory}

Berdasarkan hasil penelitian yang dilakukan bahwa pengajaran bahasa mahasiswa asing di lembaga Bimbel Education Laboratory menggunakan metode (1) Tingkat dasar, yaitu seoarang guru menejelaskan dengan secara langsung kepada mahasiswa dengan mengenalkan benda-benda, atau yang lainnya yang ada disekitarnya, dalam bentuk kata bahasa Indonesia dengan mengenalkan secara berulang-ulangan. (2) Tingkat mahir, yaitu guru melakukan pengajaran dengan menggunkan kesulitankesulitan yang dihadapi mahasiswa asing dalam pembelajaran bahasa, jadi guru mengajarkan dengan kesesuaian dimana kesulitan nya. Dalam pengajaran guru menjelaskan kepada mahasiswa dengan mengenalkan benda-benda , misalnya Dosen menjelaskan:

a. Dosen : Next to the Father is the table. The table made of wood is a table. (Disamping Bapak itu adalah meja, meja terbuat dari kayu itu adalah meja)

b. Mahasiswa : Table...table...table

$$
\text { (Meja...meja...meja) }
$$

Berdasarkan kalimat diatas bahwa Dosen Universitas Pakuan mengajarkan mahasiswa asing dengan menjelaskan benda yang disekelilingi, kemudian mahasiswa mengingat sambil mengatakan benda tersebut. Kemampuan mahasiswa asing dalam pembelajaran bahasa Indonesia mempunyai daya mengingat $87 \%$ dengan menggunakan metode tingkat dasar. Kemudian pengucapan mahasiswa penutur asing dalam mengucapkan kata atau kalimat mempunyai pengucapan kata dengan nilai $80 \%$.

Mahasiswa asing dalam pengajaran bahasa menggunakan metode yang mana tingkat mahir, yaitu guru melakukan pengajaran dengan menggunkan kesulitankesulitan yang dihadapi mahasiswa asing dalam pembelajaran bahasa, jadi guru mengajarkan dengan kesesuaian dimana kesulitan nya. Dalam pengajaran ini dosen melakukan analisis dalam membuat kalimat, mahasiswa ditugaskan membuat tugas kemudian dinilai oleh dosen kesalahan dan kesulitan mahasiswa asing dalam pembelajaran bahasa Indonesia yaitu kesalahan terdapat pemilihan kata, penggunaan afiks, kesalahan pada stuktur kalimat, dan penggunaan kefektifan dalam penggunaan 
bahasa Indonesia. Kesalahan mahasiswa asing di lembaga Bimbel Education Laboratory mendapatkan nilai $70 \%$.

b) Kesulitan Mahasiswa Penutur Asing UIN Syarif Hidayatullah Jakarta Dalam Pembelajaran Berbahasa Indonesia

Berdasarkan hasil wawancara yang dilakukan bahwa mahasiswa asing berasal dari Afrika dari Jurusan Bahasa Inggris dari UIN Syarif Hidayatullah Jakarta . bahwa kesulitan yang terdapat mahasiswa asing dalam pembelajaran pengajar tidak sepenuhnya mempersiapkan untuk mengajar BIPA di Universitas, dan kurangnya strategi pengajar dalam mengajar BIPA sehingga ini akan menimbulkan kesulitan mahasiswa asing dalam pembelajaran BIPA.

Berikut hasil kuesioner Mahasiswa Penutur Asing UIN Syarif Hidayatullah Jakarta Dalam Pembelajaran Berbahasa Indonesia:

\begin{tabular}{|r|l|c|}
\hline \multicolumn{1}{|c|}{ No } & \multicolumn{1}{|c|}{ Pemahaman Siswa } & Nilai dari Siswa \\
\hline 1. & $\begin{array}{l}\text { Dosen menjelaskan dengan baik , } \\
\text { misalnya dalam memperkenalkan } \\
\text { benda-benda yang ada disekitar kita. }\end{array}$ & $80 \%$ \\
\hline 2. & $\begin{array}{l}\text { Dosen menjelaskan secara berulang- } \\
\text { ulang agar siswa tidak merasa kesulitan } \\
\text { dalam memahami yang disampaikan } \\
\text { materi. }\end{array}$ & $87 \%$ \\
\hline 3. & $\begin{array}{l}\text { Dosen mengajarkan metode } \\
\text { pengembangan tergantung tingkat } \\
\text { kesulitan siswa. }\end{array}$ \\
\hline 4. & $\begin{array}{l}\text { Dosen memberikan bahan bacaan } \\
\text { buku bagi pemula contohnya buku } \\
\text { majalah, buku bacaan yang dibuat } \\
\text { pengajar dan buku bacaan Sekolah } \\
\text { Dasar. }\end{array}$ \\
\hline
\end{tabular}

\section{Gambar 2. Tabel Hasil Kuesioner Mahasiswa Penutur Asing UIN Syarif Hidayatullah Jakarta Dalam Pembelajaran Berbahasa Indonesia}

Berdasarkan hasil kuesioner diatas bahwa penutur asing mengalami kesulitan karena pengajar tidak memberikan proses pembelajaran yang efektif sehingga mahasiswa mengalami kesulitan. (1) Dosen menjelaskan dengan baik , misalnya dalam memperkenalkan benda-benda yang ada disekitar kita tanggapan dari siswa mendapatkan nilai 80\%. (2) Dosen menjelaskan secara berulang-ulang agar siswa tidak merasa kesulitan dalam memahami yang disampaikan materi tanggapan siswa mendapatkan nilai 87\%.(3) Dosen mengajarkan metode pengembangan tergantung tingkat kesulitan mahasiswa, tanggapan nilai dari siswa 85\%. Dan (4) Dosen memberikan bahan bacaan buku bagi pemula contohnya buku majalah, buku bacaan yang dibuat pengajar dan buku bacaan Sekolah Dasar, tanggapan nilai dari mahasiswa $85 \%$. 
c) Kesalahan Mahasiswa Penutur Asing di Lembaga Education Labotory Dalam Pembelajaran Berbahasa Indonesia

Salah satunya yang menjadi sumber data penelitian ini adalah mahasiswa penutur asing lembaga Bimbel Education Laboratory, berikut kesalahan-kesalahan dalam pembelajaran berbahasa Indonesia.

1) Kesalahan Alih kode

\begin{tabular}{|l|l|ll|}
\hline \multicolumn{1}{|c|}{ Contoh Kalimat } & \multicolumn{2}{|c|}{ Kesalahan } & \multicolumn{2}{|c|}{ Perbaikan } \\
\hline $\begin{array}{l}\text { Nah, kita sampai ke } \\
\text { hotel. Ini hotel }\end{array}$ & $\begin{array}{l}\text { 1. Pemakaian kata } \\
\text { depan. }\end{array}$ & 1. $\begin{array}{l}\text { Kata ke seharusnya } \\
\text { kata di. }\end{array}$ \\
$\begin{array}{l}\text { sangat indah dan } \\
\text { bunga-bunga di sini } \\
\text { sangat fresh. }\end{array}$ & $\begin{array}{l}\text { 2. } \begin{array}{l}\text { Penguasaan kosa } \\
\text { kata (kata asing). }\end{array} \\
\text { 2. }\end{array}$ & $\begin{array}{l}\text { Kata asing fresh } \\
\text { seharusnya segar. }\end{array}$ \\
\hline
\end{tabular}

Gambar 3. Tabel Kesalahan Alih kode

Pada dasarnya penutur asing yang belajar bahasa kedua akan melakukan alih kode dan campur kode. Data di atas menunjukan kesalahan dalam penggunaan kata depan, kesalahan pada kata ke dan di. Seharusnya kata depan ke digunakan untuk menunjukkan tujuan atau arah tertentu. Contohnya ibu akan pergi ke pasar, kalimat itu menunjukkan arah dan tujuan ibu akan pergi ke pasar tujuan nya. Tetapi pada di atas terdapat kalimat kita sampai ke hotel, kalimat tersebut tidak menunjukakan arah atau tujuan, karena ia sudah sampai ditempat yang menjadi tujuannya. Sehiangga kalimat kita sampai ke hotel memiliki kesalahan pada kata depan.

Selanjutnya kesalahan yang terdapat di campur kode, kesalahan tersebut dilakukan pada penutur asing disebabkan karena penutur asing terbiasa menggunkan bahasa inggris dalam sehari-harinya. Contohnya pada kata fresh seharusnya segar bukan menggunakan kata fresh, mungkin penutur lupa atau sudah terbiasa dengan menggunakan bahasa inggris.

\section{2) Kesalahan Pilihan Kata}

Berdasarkan hasil penelitian bentuk keasalahan pilihan kata mahasiswa penutur asing lembaga Bimbel Education Laboratory:

\begin{tabular}{|l|l|l|}
\hline \multicolumn{1}{|c|}{ Contoh Kalimat } & Kesalahan & Perbaikan \\
\hline "Selain menari di Sarang & & \\
Matahari, kami juga & Akibatnya & Sebingga atau basilnya \\
mendapatkan wawasan & \\
pengalaman yang sangat & \\
berkesan, akibatnya kami & \\
memiliki wawasan yang & & \\
luas mengenai drama & & \\
teater. & \\
\hline
\end{tabular}

Gambar 4. Tabel Kesalahan Pilihan Kata 
Pada kalimat di atas terdapat kesalahan pilihan kata yaitu akibatnya. Seharusnya yang benar adalah "Selain menari di Sarang Matahari, kami juga mendapatkan wawasan pengalaman yang sangat berkesan, sehingga kami memiliki wawasan yang luas mengenai drama teater". Kata yang benar adalah sehingga atau hasilnya, bukan kata akibatnya

\section{3) Ketidakefektifan Kalimat}

Dalam membuat kalimat seharusnya mempunyai gagasan atau ide yang ingin disampaikan dengan membuat kalimat harus jelas dan efektif sehingga dapat jelas di dengar oleh pendengar. atau tidak menggunakan kata-kata yang berlebihan (tidak boros kata). Dalam pembelajaran BIPA mahasiswa yang belajar di lembaga Bimbel Education Laboratory terdapat kesalahan dalam penggunaan kalimat yaitu:

\begin{tabular}{|l|l|l|}
\hline Contoh Kalimat & Kesalahan & Perbaikan \\
\hline $\begin{array}{l}\text { "Dari awal sekali waktu } \\
\text { pertama datang di Bogor } \\
\text { itu sangat } \\
\text { menyenangkan" }\end{array}$ & pertama waktu & Pertama kali saya \\
\hline
\end{tabular}

\section{Gambar 5. Tabel Ketidakefektifan Kalimat}

Dalam kalimat diatas terdapat kesalahan penggunaan kalimat yang tidak efektif. "Dari awal sekali waktu pertama datang di Bogor itu sangat menyenangkan", yaitu adanya penambahan subjek kalimat tersebut. Yang benar adalah kalimat Dari Pertama kali saya datang di Bogor itu sangat menyenangkan", tidak menggunakan awal sekali waktu pertama.

\section{4) Nominal Sentences}

Berikut ini adalah kesalahan penggunaan mahasiswa asing dalam lembaga Bimbel Education Laboratory dalam penggunaan nominal sentences.

\begin{tabular}{|l|l|l|}
\hline Klasifikasi dengan & Identifikasi & Perbaikan \\
\hline $\begin{array}{l}\text { Niminal, adalah rindu } \\
\text { kopula non verbal. } \\
\text { sekolah semenjak } \\
\text { covid-19. }\end{array}$ & $\begin{array}{l}\text { Saya rindu sekolah } \\
\text { semnejak covid-19. }\end{array}$ \\
\hline
\end{tabular}

\section{Gambar 6. Tabel Nominal Sentences}

Pada kalimat diatas terdapat kesalahan pada penggunaan nominal dengan kopula nonverbal. Pada kalimat diatas penggunaan kata tidak benar dan tidak tepat.

a) Saya adalah rindu sekolah semenjak covid-19.

b) Saya rindu sekolah semen

c) jak covid-19

Dalam kalimat (a), kata adalah tidak perlu dipakai dalam kalimat tersebut "pengantar predikat". Pada Kalimat (a) memiliki nomina dan frasa. Berbeda dengan contoh kalimat, dia adalah seorang dokter. Kalimat tersebut adalah salah satu penggunaan kopula yang berterima. Pada kalimat dia adalab seorang dokter subjek saya dengan predikat frasa nominal seorang dokter. Oleh karena itu, 
meskipun sama sama menggunkan kata adalah tetapi kedua contoh kalimatnya berbeda.

\section{5) Kesalahan Adpositions}

Berikut ini adalah kesalahan penggunaan mahasiswa asing dalam lembaga Bimbel Education Laboratory dalam penggunaan Kesalahan Adpositions:

\begin{tabular}{|l|l|l|}
\hline Klasifikasi & Identifikasi & Perbaikan \\
\hline Frasa preposisional & $\begin{array}{l}\text { (a) Saya mau membawa } \\
\text { laptop } \\
\text { perpustakaan. }\end{array}$ & $\begin{array}{l}\text { Saya mau membawa } \\
\text { buku ke perpustakaan. }\end{array}$ \\
\hline
\end{tabular}

\section{Gambar 7. Tabel Kesalahan Adpositions}

Pada kalimat diatas terdapat kesalahan penggunaan preposisi. Yaitu pada kalimat (a) Saya mau membawa laptop di perpustakaan, kata di- berfungsi menyatakan tempat. Sedangkan preposisi ke- lebih tepatnya menyatakan arah tujuan. Meskipun kata ke- masih berhubungan dengan tempat. Maka pada kalimat (a) tidak tepat dalam penggunaan preposisi.

\section{SIMPULAN DAN SARAN}

Berdasarkan hasil penelitian yang dilakukan bahwa pengajaran bahasa yang dilakukan di Lembaga Education Labotory Dalam Pembelajaran Berbahasa Indonesia, pengajaran BIPA di lembaga Bimbel Education Laboratory menggunakan metode pengajaran : (1) Tingkat dasar, yaitu seoarang guru menejelaskan dengan secara langsung kepada mahasiswa dengan mengenalkan benda-benda, atau yang lainnya yang ada disekitarnya, dalam bentuk kata bahasa Indonesia dengan mengenalkan secara berulang-ulangan. (2) Tingkat mahir, yaitu guru melakukan pengajaran dengan menggunkan kesulitan- kesulitan yang dihadapi mahasiswa asing dalam pembelajaran bahasa, jadi guru mengajarkan dengan kesesuaian dimana kesulitan nya.

Mahasiswa asing di Lembaga Education Labotory Dalam Pembelajaran Berbahasa Indonesia dalam pembelajaran BIPA Sedangkan untuk kesalahankesalahan mahasiswa penutur asing lembaga Bimbel Education Laboratory adanya kesalahan pemilihan kata, pengguanakan afiks, kesalahan pada penggunaan struktur kalimat, dan penggunaan kefektifan kalimat dalam penggunaan bahasa Indonesia. Agar mahasiswa asing tidak kesulitan dalam pembelajaran bahasa sebaiknya pengajar mengetahui apa kesulitan mahasiswa asing, dan pengajar harus mempunyai strategi yang kreatif agar tidak menyebabkan mahasiswa asing belajar bahasa Indonesia.

Saran dari Penelitian semoga peneliti bermanfaat bagi kita semua, khususnya bagi pembelajar penutur asing dalam pembelajaran BIPA, dan semoga ini bermanfaat untuk semua kalangan pengajar yang akan mengajar pembelajaran BIPA.

\section{DAFTAR PUSTAKA}

Kusmiatun, Ari. (2016). Mengenal BIPA dan Pembelajarannya. Yogyakarta: K Media. 
Pengajaran Bahasa Dan Pemerolehan Bahasa Kedua...

Nuryani, (2013). Psikolingustik. Ciputat: Mazhab Ciputat.

Suyitno, I. (2017), Norma Pedagois Pembelajaran Bahasa Indonesia untuk Penutur Asing. Bandung: PT. Refika Aditama. 